\title{
Rice in vitro digestion: application of INFOGEST harmonized protocol for glycemic index determination and starch morphological study
}

\author{
Jean-M. Fernandes ${ }^{1} \cdot$ Daniel A. Madalena ${ }^{1} \cdot$ Ana C. Pinheiro $^{1}\left(\mathbb{D} \cdot{\text { António A. } \text { Vicente }^{1}}^{1}\right.$
}

Revised: 24 October 2019/Accepted: 12 November 2019/Published online: 18 November 2019

(C) Association of Food Scientists \& Technologists (India) 2019

\begin{abstract}
Starch is the main sugar source present in staple foods. Understanding starch hydrolysis during digestion and the resulting glucose release can be important to strategically modulate starch digestion and glucose absorption. In vitro digestion methodologies are fundamental to evaluate starch hydrolysis length and rate, but the lack of uniformity between protocols prevent the comparison of results. In this context, three different Carolino rice varieties (i.e., Carolino white- $\mathrm{Cw}$, Carolino brown $-\mathrm{Cb}$ and Carolino Ariete brown-CAb) were submitted to the INFOGEST harmonized in vitro digestion protocol for the evaluation of starch hydrolysis and subsequent glycemic index (GI) determination, and starch granules morphological study. Samples of Carolino rice presented total starch percentages between 64.52 (for $\mathrm{Cb}$ ) to $71.52 \%$ (for $\mathrm{Cw}$ ) with low amylose content (16.19-19.95\%, varying in the following order $\mathrm{Cb}<\mathrm{Cab} \approx \mathrm{Cw})$. During digestion, between 39.43 (for $\mathrm{CAb}$ ) to $44.48 \%$ (for $\mathrm{Cb}$ ) of starch was hydrolyzed, classifying samples as medium GI foods (61.73-69.17). Starch hydrolysis was accompanied by a decrease of starch granules dimensions. For all samples, area decrease was higher than $59 \%$, perimeter decrease was higher than $37 \%$, feret diameter decrease was higher than $39 \%$ and minimum feret diameter decrease was higher than $32 \%$. This work provides new insights to describe, both qualitatively and quantitatively, the fate of rice during digestion, and allowed establishing a comparative basis for the development of rice-based recipes with a lower GI.
\end{abstract}

Ana C. Pinheiro

anapinheiro@deb.uminho.pt

1 CEB - Centre of Biological Engineering, University of Minho, 4710-057 Braga, Portugal
Keywords Rice starch hydrolysis - Rice starch morphology · Glycemic index · In vitro digestion . Digestion protocols

\section{Introduction}

Rice is among the most consumed staple foods, representing the main source of carbohydrates for an estimated 3.5 billion people, of which nearly $50 \%$ is represented by China and India (Muthayya et al. 2014). Rice grains have high starch content, representing up to $90 \%$ of the grain (dry weight basis) (Juliano 1993; Patindol et al. 2015). The hydrolysis of this polymeric carbohydrate is caused mainly by $\alpha$-amylase and pancreatic enzymes during the digestion process, in which it is primarily released as maltose, that is further broken down into two glucose molecules thus becoming available for absorption (Tester et al. 2006).

Rice consumption can significantly raise blood glucose levels (Chang et al. 2014), being generally described as a high glycemic index (GI) food. The GI of a food is a kinetic parameter which is determined as the increment in the blood sugar concentration after the consumption of that food compared with a standard food (normally white bread) (Jenkins et al. 2002). GI is considered a more accurate measurement than the caloric content, because it contemplates the rate and extension of digestion and sugar absorption (Ludwig 2002).

One parameter of interest when studying GI of starchy foods is its amylose content (Srikaeo and Sangkhiaw 2014). Amylose and amylopectin are the components of starch, with linear and branched chain structures, respectively. Due to its more compact structure, amylose is more resistant to enzyme action. Therefore, the amylose content is also correlated with starch digestibility, which can be 
described as rapidly digestible starch (RDS), slowly digestible starch (SDS) and resistant starch (RS) (Deepa et al. 2010). In this sense, high amylose content is correlated with a higher percentage of RS (Srikaeo and Sangkhiaw 2014), that in consequence will result in a lower GI.

GI of a food product is also influenced by its form, postharvesting processing, cooking procedure and even conservation process (Björck et al. 1994).

Rice with lower amylose content (i.e., waxy rice; Japonica varieties) will have higher retrogradation than rice with higher amylose content, thus presenting a pasty texture after cooking. The presence or absence of bran will affect the water absorption capacity of the grain and, therefore, brown rice requires longer cooking times and a higher water volume (Roy et al. 2008).

GI determination of starchy foods using an in vitro methodology was firstly described by Goñi et al. (1997) and since then, in vitro protocols have been applied in various products to study the effect of different characteristics and processing methods on the GI value. These protocols are often modified to fulfill the experiment requirements, thus lacking the necessary uniformity to allow comparison between different studies. More recently, a consensus protocol was proposed by the COST action INFOGEST (Minekus et al. 2014). This protocol was developed in order to mimic physiologic in vivo parameters of the human gastrointestinal tract, providing a rapid and easy standardized method for analysis of food or pharmaceuticals behavior during the digestion process. It has been applied to some food matrices (Egger et al. 2016), prebiotics (Nobre et al. 2018), probiotics (Ramos et al. 2016), compounds of interest (Rodrigues et al. 2017), different cereals (Bustos et al. 2017) and more recently, rice (Azizi et al. 2019).

In this context, this study aims at assessing of the GI of three different Carolino rice varieties, Carolino white $(\mathrm{Cw})$, Carolino brown $(\mathrm{Cb})$ and Carolino Ariete brown $(\mathrm{Cab})$, by the application of the INFOGEST harmonized in vitro digestion protocol, for the first time in Carolino rice varieties, taking advantage of its robustness and the use of more realistic conditions. Three different Carolino rice varieties have been chosen for this study once it is the type of rice most consumed in Portugal, which is the Europe's biggest rice consumer. Moreover, the morphology of the rice grains was also evaluated during the digestion process using fluorescence spectroscopy to assess starch digestion qualitatively. Finally, the results were compared with extensive literature data on starch digestion and conclusions were drawn about the compatibility of the existing in vitro digestion methodologies.

\section{Materials and methods}

\section{Rice samples and their preparation}

The samples used in this work were provided by Ernesto Morgado S.A. (Alqueidão, Portugal). The three rice varieties used were from Japonica species (Oryza sativa), specifically a commercially available cultivar Carolino white rice $(\mathrm{Cw})$ branded "Pato Real Malandrinho", cv. Carolino brown rice $(\mathrm{Cb})$ and $\mathrm{cv}$. Carolino Ariete brown rice $(\mathrm{CAb})$ (newest Portuguese variety of cultivar Carolino rice).

Rice grains length and width were measured using a micrometer (No. 293-5, Mitutoyo, Japan) $(n=12)$, for size and shape characterization. Grain size was categorized by its length and its shape was categorized by its length-width ratio.

Prior to the application of the digestion protocol, rice samples were cooked and grinded. For the cooking process, an electric rice cooker was used (Ref. 968935000, Rice Chef Compact, Taurus, Spain) in order to maintain the same conditions in every cooking process. Preliminarily tests (data not shown) have been conducted to determine the adequate rice and water amounts for the complete cooking of each rice variety. According to these tests, $62.5 \mathrm{~g}$ of $\mathrm{Cw}$ rice plus $160 \mathrm{~mL}$ of water and $70 \mathrm{~g}$ of $\mathrm{Cb}$ or $\mathrm{CAb}$ rice plus $320 \mathrm{~mL}$ of water have been used. In order to mimic the mechanic degradation due to mastication while keeping the uniformity of this operation, rice was grinded in a food grinder (VM-4210, Tristar, Netherlands) mounted with the included fine cutting plate (XX-4210230, Tristar, Netherlands).

\section{Total starch quantification}

For the determination of the rice total starch, the Total Starch Assay Kit (AA/AMG), from Megazyme (K-TSTA, Ireland) was used. Briefly, samples were milled, weighed $(100 \mathrm{mg})$, and incubated with $5 \mathrm{~mL}$ of ethanol $80 \%(\mathrm{v} / \mathrm{v})$ at $80{ }^{\circ} \mathrm{C}$ for $5 \mathrm{~min}$. Another $5 \mathrm{~mL}$ of ethanol $80 \%$ (v/v) were added before centrifugation at $1800 \mathrm{~g}$ for $10 \mathrm{~min}$ (EBA 20, Hettich, Germany). The supernatant was discarded and samples were washed and centrifuged again under the same conditions with $10 \mathrm{~mL}$ of ethanol. Then $2 \mathrm{~mL}$ of $\mathrm{KOH}$ $2 \mathrm{~mol} \mathrm{~L}^{-1}$ was added while stirring on cold water (at $4{ }^{\circ} \mathrm{C}$ ), which helped to hydrolyze resistant starch. After 20 min of stirring, samples were neutralized with $8 \mathrm{~mL}$ of sodium acetate buffer $1.2 \mathrm{~mol} \mathrm{~L}^{-1}$ (i.e., $\mathrm{pH}$ 3.8) and $0.1 \mathrm{~mL}$ of thermostable $\alpha$-amylase $(3.000 \mathrm{U} / \mathrm{mL}$ on Ceralpha reagent at $\mathrm{pH} 6.5$ and $40{ }^{\circ} \mathrm{C}$ or $1.600 \mathrm{U} / \mathrm{mL}$ on Ceralpha reagent at pH 5.0 and $40^{\circ} \mathrm{C}$, Megazyme, Ireland) and $0.1 \mathrm{~mL}$ of amyloglucosidase $(3.300 \mathrm{U} / \mathrm{mL}$ on soluble 
starch or $200 \mathrm{U} / \mathrm{mL}$ on p-nitrophenyl $\beta$-maltoside at $\mathrm{pH} 4.5$ and $40{ }^{\circ} \mathrm{C}$, Megazyme, Ireland) were added. These enzymes hydrolyze starch into soluble maltodextrins $(\alpha-$ amylase enzymatic digestion) to be further hydrolyzed into D-glucose (amyloglucosidase enzymatic digestion). In the final step, D-glucose is oxidized to D-gluconate, by glucose oxidase-peroxidase (GOPOD), releasing hydrogen peroxide which is then consumed with p-hydroxybenzoic acid and 4-aminoantipyrine to produce quinoneimine dye, during incubation at $50{ }^{\circ} \mathrm{C}$ for $20 \mathrm{~min}$. The absorbance of this colorimetric reaction was read at $510 \mathrm{~nm}$ (V560, Jasco, Italy) and percentage of D-glucose in samples $(100 \mathrm{mg})$ was calculated. Total starch was obtained by multiplying the percentage of D-glucose by the conversion factor (162/ 180 ), that represents anhydrous D-glucose and free D-glucose molecular weight, respectively.

\section{Amylose and amylopectin quantification}

Amylose content was determined by the standardized protocol ISO 6647-1, Rice-Determination of amylose content, for rice samples with amylose content ranging from 1 to $30 \%$. Briefly, $100 \mathrm{mg}$ of milled rice sample was weight and $1 \mathrm{~mL}$ of ethanol $95 \%(\mathrm{v} / \mathrm{v})$, and $9.0 \mathrm{~mL}$ of sodium hydroxide solution $1 \mathrm{~mol} \mathrm{~L}^{-1}$ was added. Starch was dispersed by heating the samples on a boiling water bath for $10 \mathrm{~min}$. The solution was made up to $100 \mathrm{~mL}$. For color development, $5 \mathrm{~mL}$ of the previously treated sample was used and $1 \mathrm{~mL}$ of acetic acid $1 \mathrm{~mol} \mathrm{~L}^{-1}$ and $2 \mathrm{~mL}$ of iodine solution (iodine $8 \mathrm{mmol} \mathrm{L}^{-1}$ with potassium iodide $0.12 \mathrm{~mol} \mathrm{~L}^{-1}$ ) was added and made up to $100 \mathrm{~mL}$. The absorbance of samples was read at $620 \mathrm{~nm}$ (V560, Jasco, Italy), and the corresponding concentration was calculated using a plotted calibration curve using pure amylose from potato (Sigma-Aldrich A0512; CAS 9005-82-7). The amylopectin content was indirectly determined, subtracting the amylose percentage to the total starch percentage of the sample.

\section{Static in vitro digestion}

The consensus INFOGEST protocol was followed for the static in vitro digestions (Minekus et al. 2014). The procedure is composed by an oral, gastric and small intestinal phase (with the possibility of continuation to a large intestinal phase). Simulated digestion fluids (i.e., Simulated Salivary Fluid (SSF: $\mathrm{KCl} 15.1 \mathrm{mmol} \mathrm{L}{ }^{-1}, \quad \mathrm{KH}_{2} \mathrm{PO}_{4}$ $3.7 \mathrm{mmol} \mathrm{L}^{-1}, \mathrm{NaHCO}_{3} 13.6 \mathrm{mmol} \mathrm{L}^{-1}, \mathrm{MgCl}_{2}\left(\mathrm{H}_{2} \mathrm{O}\right)_{6}$ $0.15 \mathrm{mmol} \mathrm{L}^{-1}, \quad\left(\mathrm{NH}_{4}\right)_{2} \mathrm{CO}_{3} \quad 0.06 \mathrm{mmol} \mathrm{L}^{-1}, \quad \mathrm{HCl}$ $1.1 \mathrm{mmol} \mathrm{L}^{-1}$ ); Simulated Gastric Fluid (SGF: $\mathrm{KCl}$ $6.9 \mathrm{mmol} \mathrm{L}^{-1}, \quad \mathrm{KH}_{2} \mathrm{PO}_{4} \quad 0.9 \mathrm{mmol} \mathrm{L}^{-1}, \quad \mathrm{NaHCO}_{3}$ $25 \mathrm{mmol} \mathrm{L}^{-1}, \quad \mathrm{NaCl} \quad 47.2 \mathrm{mmol} \mathrm{L}^{-1}, \quad \mathrm{MgCl}_{2}\left(\mathrm{H}_{2} \mathrm{O}\right)_{6}$
$0.1 \mathrm{mmol} \mathrm{L}^{-1}, \quad\left(\mathrm{NH}_{4}\right)_{2} \mathrm{CO}_{3} \quad 0.5 \mathrm{mmol} \mathrm{L}^{-1}, \quad \mathrm{HCl}$ $15.6 \mathrm{mmol} \mathrm{L}^{-1}$ ); Simulated Intestinal Fluid (SIF: $\mathrm{KCl}$ $6.8 \mathrm{mmol} \mathrm{L}^{-1}, \quad \mathrm{KH}_{2} \mathrm{PO}_{4} \quad 0.8 \mathrm{mmol} \mathrm{L}^{-1}, \quad \mathrm{NaHCO}_{3}$ $85 \mathrm{mmol} \mathrm{L}^{-1}, \quad \mathrm{NaCl} \quad 38.4 \mathrm{mmol} \mathrm{L}^{-1}, \quad \mathrm{MgCl}_{2}\left(\mathrm{H}_{2} \mathrm{O}\right)_{6}$ $0.33 \mathrm{mmol} \mathrm{L}^{-1}, \quad \mathrm{HCl} 8.4 \mathrm{mmol} \mathrm{L}^{-1}$ )) were prepared $1.25 \times$ concentrated, allowing the subsequent addition of enzyme solution and $\mathrm{CaCl}_{2}\left(\mathrm{H}_{2} \mathrm{O}\right)_{2}$ (i.e., $0.75 \mathrm{mmol} \mathrm{L}^{-1}$ in SSF, $0.075 \mathrm{mmol} \mathrm{L}^{-1}$ in SGF and $0.3 \mathrm{mmol} \mathrm{L}^{-1}$ in SIF). The experiments were performed in a water bath (B. BRAUN BIOTECH model CERTOMAT WR, Melsungen, Germany) with horizontal agitation $(120 \mathrm{rpm})$ at $37^{\circ} \mathrm{C}$.

For the oral phase, a ratio of food to SSF of 50:50 (w/v) was considered and $\alpha$-amylase was added (Sigma-Aldrich A1031, CAS 9000-90-2) to obtain $75 \mathrm{U} / \mathrm{mL}$ activity. The mixture was incubated for $2 \mathrm{~min}$. The gastric phase consisted in the addition of SGF and pepsin (Sigma-Aldrich P7012; CAS 9001-75-6) to a final ratio of food to SGF of 50:50 (v/v) and enzyme activity of $2000 \mathrm{U} / \mathrm{mL}$. At this point, $\mathrm{pH}$ was adjusted to 3.0 using $\mathrm{HCl} 1 \mathrm{mmol} \mathrm{L}^{-1}$ and the mixture was incubated for $120 \mathrm{~min}$. The intestinal phase was simulated by adding SIF to the gastric chyme in a final ratio of 50:50 (v/v). Pancreatin (Sigma-Aldrich P7545; CAS 8049-47-6) was added to obtain 100 (TAME: one unit hydrolyses $1 \mu \mathrm{mol}$ of $p$-toluene-sulfonyl-L-arginine methyl ester (TAME) per minute at $25^{\circ} \mathrm{C}, \mathrm{pH}$ 8.1) $\mathrm{U} / \mathrm{mL}$ activity, as well as bile salts (Sigma-Aldrich B8631; CAS 8008-63-7) in a concentration of $80.0 \mathrm{mg} / \mathrm{mL}$. pH was then adjusted to 7.0 using $\mathrm{NaOH} 1 \mathrm{mmol} \mathrm{L}^{-1}$ and the mixture was incubated for $120 \mathrm{~min}$.

This protocol was applied to evaluate starch hydrolysis and also to evaluate morphological changes in the rice starch granules (RSG).

\section{Starch hydrolysis evaluation}

For the determination of the starch hydrolysis, $5 \mathrm{~g}$ of cooked and grinded rice were added into a $50 \mathrm{~mL}$ Falcon tube, and samples were collected from the liquid medium in the end of the oral phase $(2 \mathrm{~min})$ and subsequently each $30 \mathrm{~min}$ until the end of the digestion process $(240 \mathrm{~min})$. Collected samples were centrifuged at $1800 \mathrm{~g}$ for $10 \mathrm{~min}$ (EBA 20, Hettich, Germany) and supernatant was used for glucose quantification using GOPOD reagent as described in total starch determination. Samples were incubated with GOPOD reagent at $50{ }^{\circ} \mathrm{C}$ for $20 \mathrm{~min}$ and afterwards absorbance was read at $510 \mathrm{~nm}$ (V560, Jasco, Italy). The obtained percentages of D-glucose were converted to percentages of starch with a 0.9 factor (division of starch occurring anhydrous D-glucose by free D-glucose molecular weight). Obtained values of starch available were normalized to percentage of hydrolysed starch. 


\section{Calculation of glycemic index, rapidly digestible starch, slowly digestible starch and resistant starch}

Glucose concentration quantified during the digestion process was normalized to percentage of total starch hydrolyzed, so that the GI index of the samples can be determined using the area under the curve (AUC). AUC of total starch hydrolyzed during the digestion was calculated manually as the sum (0-240 min) of areas between sample points, considering the area of the trapezium formed by the points in the graph (Eq. 1):

$A U C_{2-30}=\frac{\% H S_{2}+\% H S_{30}}{2} * t_{2-30}$

where $A U C_{2-30}$ represents the area between 2 and $30 \mathrm{~min}$, $H S_{2}$ represents the percentage of total starch hydrolysed after $2 \mathrm{~min}, H S_{30}$ represents the percentage of total starch hydrolysed after $30 \mathrm{~min}$ and $t$ represents the time between 2 and $30 \mathrm{~min}$. The $A U C$ of both sample and reference food (starch from potato; 121096.1211 Panreac, Spain) were used to calculate the hydrolysis index $(H I)$ as described by Goñi et al. (1997), according to Eq. (2):

$H I=\frac{A U C_{\text {sample }}}{A U C_{\text {ref }}} * 100$

where $A U C_{\text {sample }}$ corresponds to the $A U C$ of the rice sample and $A U C_{r e f}$ corresponds to the $A U C$ of the reference food. GI was then determined according to Eq. (3):

$G I=39.71+(0.549 * H I)$

Using the data obtained in the in vitro digestion, starch fractions corresponding to rapidly digestible starch (RDS), slowly digestible starch (SDS), and resistant starch (RS) were determined by Eqs. (4)-(6), based on those described by Englyst et al. (1999) with modifications, considering RDS as starch hydrolysed during the oral phase, SDS as the maximum amount of starch hydrolysed during gastricintestinal phase and RS as starch that was not hydrolysed

$\% \mathrm{RDS}=\% \mathrm{HS}_{2}$

$\% S D S=\% H S_{180}-\% H S_{2}$

$\% R S=T S-\% H S$

where $\mathrm{HS}_{2}$ represents the percentage of total starch hydrolysed after $2 \mathrm{~min}, H S_{180}$ represents the percentage of total starch hydrolysed after $180 \mathrm{~min}, H S$ represents the percentage of total starch hydrolysed until the end of the digestion, and TS represents the total starch (i.e., 100\%).

Starch hydrolysis rate $(H R)$ throughout the digestion procedure was determined by Eq. (7).

$H R_{2-30}=\frac{\% H S_{30}-\% H S_{2}}{t_{2-30}}$

\section{Fluorescence microscopy}

For the observation of RSG with fluorescence microscopy, staining agents' safranin $\mathrm{O}$ (Acros Organics AC146640250; CAS 477-73-6), rhodamine B (Alfa Aesar A13572-18; CAS 81-88-9) and fluorescein-5,6-isothiocyanate (FITC) (Fluka 46950; CAS 27072-45-4) were tested since they were previously used by other authors to stain starch (van de Velde et al. 2002). Briefly, and according to these previous works, rice samples were stained (i.e., $20 \mu \mathrm{L}$ of FITC/rhodamine in a concentration of $2.0 \mathrm{mg} / \mathrm{mL}$ and $30 \mu \mathrm{L}$ of safranin in a concentration of $5.0 \mathrm{mg} / \mathrm{mL}$ ), and washed 3 times with distilled water (i.e., centrifugation at $1800 \mathrm{~g}$ for $10 \mathrm{~min}$ (EBA 20, Hettich, Germany), discarding supernatant between washes). To assess the morphological changes in RSG, $500 \mathrm{mg}$ of cooked and grind rice were added into ten individual $15 \mathrm{~mL}$ Falcon tubes and submitted to static in vitro digestion. Samples correspondent to the content of one Falcon tube were collected in the same time periods as for the starch hydrolysis experiment for posterior microscopic observation and correlation. RSG were visualized in an Olympus BX51 (Olympus Europa, Hamburg, Germany) fluorescence microscopy with a wavelength filter $\left(\lambda_{\mathrm{ex}}\right.$ $=488 \mathrm{~nm} ; \lambda_{\mathrm{em}}=500$ to $525 \mathrm{~nm}$ ) and magnification of $10 \times$ and $40 \times$. For RSG dimensions analysis, 10 pictures with $40 \times$ magnification were taken for each point of the digestion process (i.e., $2 \mathrm{~min}$ and each $30 \mathrm{~min}$ afterwards). RSG pictures were analyzed and measured (area, perimeter, Feret diameter and minimum Feret diameter) using Image J software.

\section{Statistical analysis}

The statistical analyses related to the current experimental data were performed using the statistical software GraphPad Prism software version 7.04 (GraphPad, USA). The statistical significance of different samples (at $p \leq 0.05$ ) was determined using one-way ANOVA followed by post hoc. Tukey's honestly significant difference (HSD) test. Unless otherwise stated, all the following experiments were run at least in triplicate and all measured parameters are means of experimental points.

\section{Results and discussion}

\section{Rice properties}

Kernels measurements (data not shown) demonstrates that all rice samples can be classified as long grain rice 
Table 1 Percentages of total starch and amylose content of $\mathrm{Cw}, \mathrm{Cb}$ and $\mathrm{CAb}$ rice samples

\begin{tabular}{llllllll}
\hline & Total starch $(\%)$ & Amylose $(\%)$ & Amylopectin $(\%)$ & $\%$ RDS & $\%$ SDS & $\%$ RS & GI \\
\hline $\mathrm{CW}$ & $71.52 \pm 0.74^{\mathrm{a}}$ & $19.95 \pm 1.03^{\mathrm{a}}$ & $51.57 \pm 1.27^{\mathrm{a}}$ & $3.82 \pm 0.32^{\mathrm{a}}$ & $37.00 \pm 1.56^{\mathrm{a}}$ & $59.72 \pm 1.53^{\mathrm{a}}$ & $67.84 \pm 3.59^{\mathrm{a}}$ \\
$\mathrm{Cb}$ & $64.52 \pm 3.55^{\mathrm{b}}$ & $16.20 \pm 0.67^{\mathrm{b}}$ & $48.32 \pm 3.61^{\mathrm{a}}$ & $5.19 \pm 1.73^{\mathrm{b}}$ & $39.29 \pm 2.77^{\mathrm{a}}$ & $55.53 \pm 2.17^{\mathrm{b}}$ & $69.60 \pm 5.94^{\mathrm{a}}$ \\
$\mathrm{CAb}$ & $65.47 \pm 3.15^{\mathrm{b}}$ & $19.45 \pm 0.57^{\mathrm{a}}$ & $46.03 \pm 3.20^{\mathrm{a}}$ & $1.50 \pm 1.49^{\mathrm{c}}$ & $37.93 \pm 3.89^{\mathrm{a}}$ & $60.57 \pm 3.59^{\mathrm{a}}$ & $62.28 \pm 5.51^{\mathrm{a}}$ \\
\hline
\end{tabular}

RDS, SDS, RS and GI values determined for $\mathrm{Cw}, \mathrm{Cb}$ and $\mathrm{CAb}$ rice samples. Values presented correspond to mean and standard deviations deviation on a dry basis

Mean values within the same column, labelled with the same superscript letter (a, b or c) do not statistically differ from each other $(p>0.05)$

(length $>6.0 \mathrm{~mm}$ and length/width ratio $\geq 3$ ) taking into consideration the reported standard for rice (Codex Alimentarius 1995). Dimensions observed are in accordance with the values found in literature for Japonica rice species (Carolino) (Santos et al. 2015). Percentages of total starch, amylose and amylopectin are depicted in Table 1.

It is possible to observe that, as expected, $\mathrm{Cw}$ sample exhibits the higher percentage of total starch, once their kernels are mainly composed by the endosperm of the seed as a result of the milling process, and it is in the endosperm that RSG are stored. Amylose content values vary between 16 and 20\%, characterizing all samples as low-amylose cultivars (Juliano 1993). Due to the higher percentage of total starch, $\mathrm{Cw}$ also presented the highest amylopectin content. These values are expected for Carolino rice varieties, since this variety belongs to Oryza sativa subspecies Japonica rice, categorised as sticky variety (Chang et al. 2014).

\section{In vitro digestion-starch hydrolysis}

Figure 1 represents the profile of total starch hydrolysed during in vitro digestion for $\mathrm{Cw}, \mathrm{Cb}$ and $\mathrm{CAb}$. For all samples, the action of $\alpha$-amylase alone during the oral

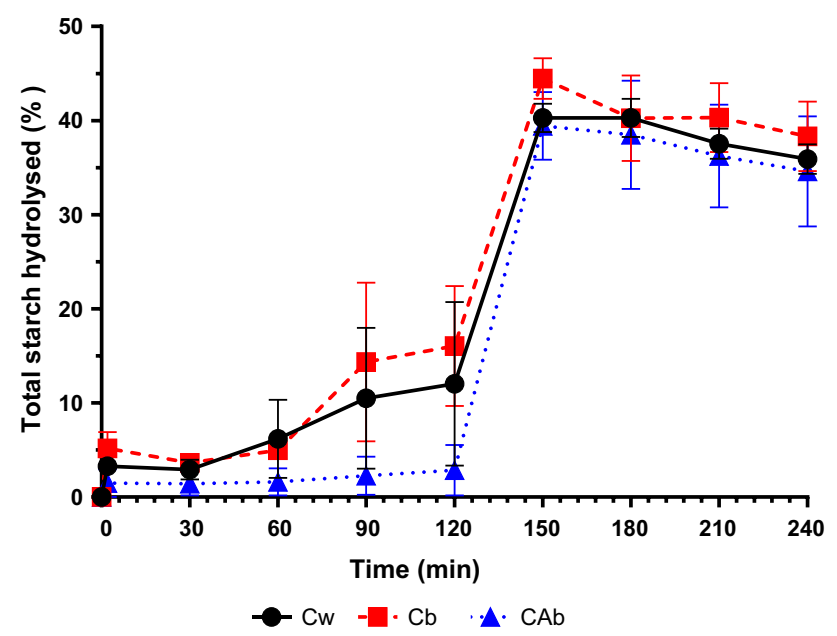

Fig. 1 Total starch hydrolysed during in vitro digestion of $\mathrm{Cw}, \mathrm{Cb}$, and $\mathrm{CAb}$ phase was not very pronounced, hydrolyzing less than 3\% of total starch from $\mathrm{CAb}$ to less than $7 \%$ of total starch from $\mathrm{Cb}$. This step of the digestion is very short (only $2 \mathrm{~min}$ ) and therefore, there is not enough time for a significant action of this enzyme, which is then stopped when in contact with the acidic medium characteristic of the gastric phase (Whitcomb and Lowe 2007). Despite the low enzyme activity in the oral phase, starch hydrolysis rate in this phase is the highest throughout the digestion, for all samples (i.e., $1.64 \% / \mathrm{min}, 2.59 \% / \mathrm{min}$ and $0.75 \% / \mathrm{min}$ for $\mathrm{Cw}, \mathrm{Cb}$ and $\mathrm{CAb}$, respectively).

In the gastric phase of the in vitro digestion, $\mathrm{CAb}$ samples were more resistant to enzymatic digestion when compared to $\mathrm{Cb}$ and $\mathrm{Cw}$ samples (i.e., \% of hydrolyzed starch of $12.02 \pm 8.71 \%, \quad 16.04 \pm 6.38 \% \quad$ and $2.87 \pm 2.68 \%$, for $\mathrm{Cw}, \mathrm{Cb}$ and $\mathrm{CAb}$, respectively). At this phase, starch hydrolysis is commonly associated to the enzymatic activity of pepsin, which breaks down the protein layer $(0.1-0.7 \%$ of starch weight) found at the surface and inside the starch (Pérez and Bertoft 2010). The action of this enzyme provoked alterations on starch structure by hydrolyzing protein layers, but was not significant and specific for starch hydrolysis, which is reflected in the low starch hydrolysis rate of the gastric phase (i.e., $0.07 \% / \mathrm{min}$, $0.09 \% / \mathrm{min}$ and $0.01 \% / \mathrm{min}$ for $\mathrm{Cw}, \mathrm{Cb}$ and $\mathrm{CAb}$, respectively).

It is also possible to observe that, for all rice samples, there was a rapid starch hydrolysis in the gastric-intestinal transition (i.e., from 120 to $150 \mathrm{~min}$ ). The starch hydrolysis rate in this transition is comparable to the starch hydrolysis rate of the oral phase (i.e., $0.94 \% / \mathrm{min}, 0.95 \% / \mathrm{min}$ and $1.22 \% / \mathrm{min}$ for $\mathrm{Cw}, \mathrm{Cb}$ and $\mathrm{CAb}$, respectively). For all samples, the highest values of starch hydrolysis were observed in the first point of the intestinal phase, at $150 \mathrm{~min}$. This peak of hydrolysis can be associated with the addition of pancreatin (mixture of amylase, proteases and lipases), which benefits from the neutral environment found in the intestine (i.e., $\mathrm{pH}$ 7.0). The results obtained indicate a rapid starch hydrolysis (in less than $30 \mathrm{~min}$ ) when submitted to pancreatin, which is expected, since it is reported that the enzymatic activity of pancreatic amylase is higher than that of $\alpha$-amylase (Woolnough et al. 2010). 


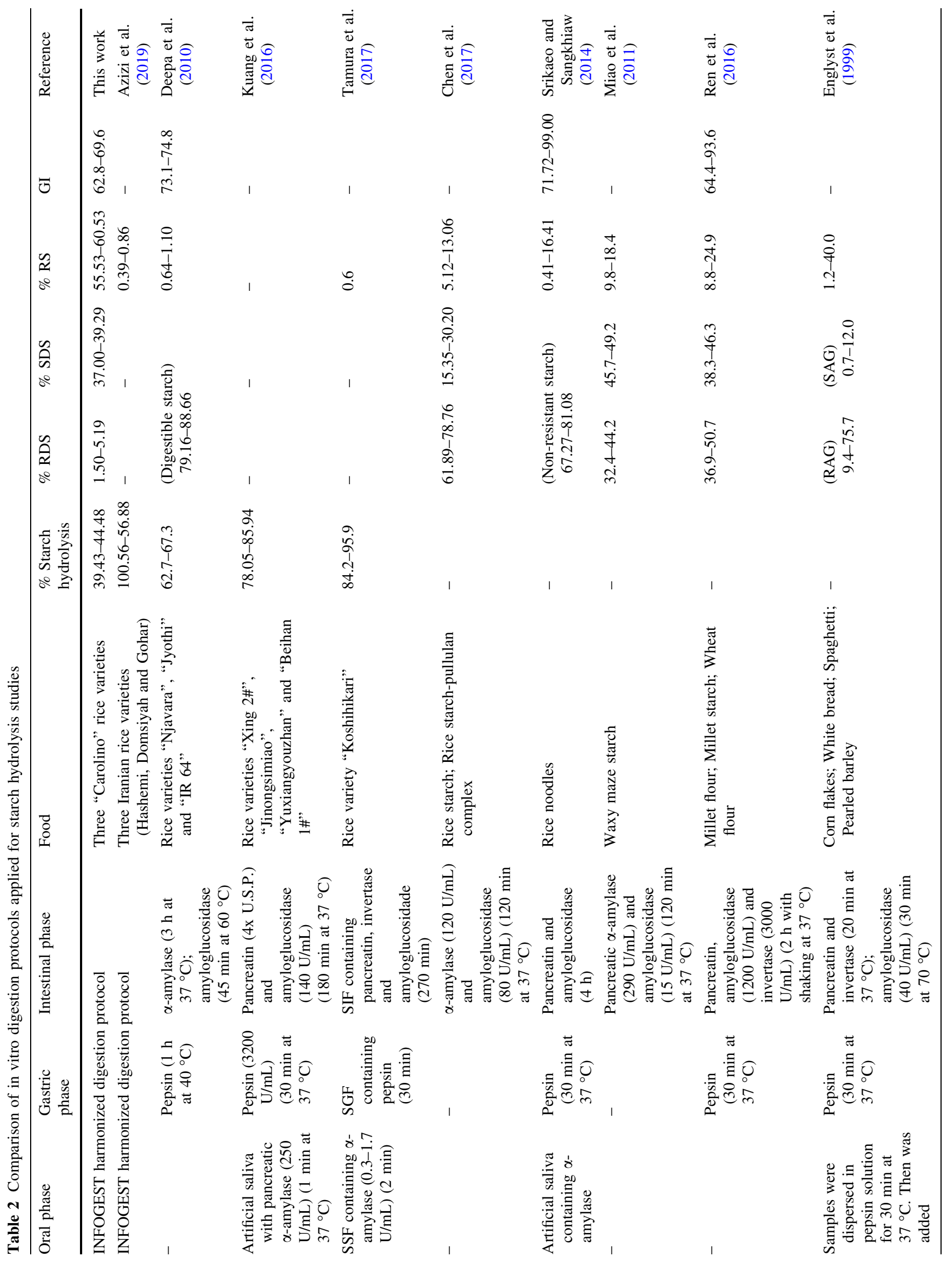




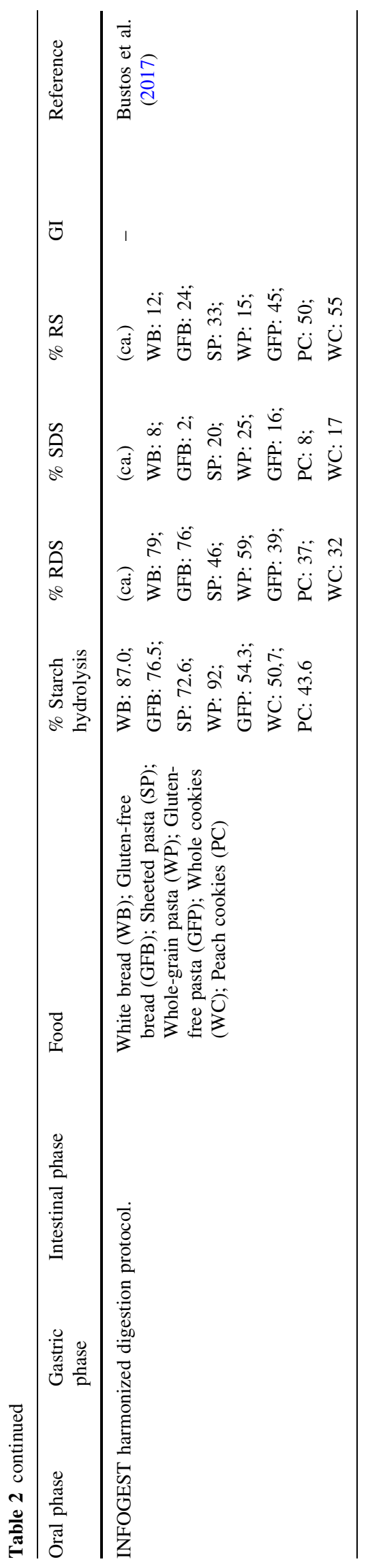

The final values of total starch hydrolysis were $40.28 \pm 1.53 \%, 44.48 \pm 2.17 \%$ and $39.43 \pm 3.59 \%$ for $\mathrm{Cw}, \mathrm{Cb}$ and $\mathrm{CAb}$, respectively. Therefore, only the sample $\mathrm{Cb}$ presented significant statistical differences in terms of percentage of total starch hydrolyzed (i.e., $p<0.05$, Tukey test). Even though integral rice is known as being more resistant to hydrolysis, which is consequently associated with lower GI, the results obtained can be related to the fact that this sample also presented the lowest amylose content of the three samples, which is more resistant to the enzymatic attack due to its linear structure (Srikaeo and Sangkhiaw 2014). Besides its amylose/amylopectin content and molecular/supra molecular structure, also the intrinsic characteristics of each cultivar (e.g. cell wall intactness, granule/particle size, level of proteins and interactions with starch granules) can be considered key factors in controlling the rate and extent of starch hydrolysis in rice grains (Azizi et al. 2019).

Some results previously described in the literature (Tamura et al. 2017) are not in agreement with the hydrolysis profiles obtained here. The differences found are presumably due to the use of different in vitro digestion protocols: many of those found in the literature do not simulate each digestion phase separately, thus resulting in a continuously increasing starch hydrolysis and use different enzymes with different activities. In fact, a wide range of in vitro digestion protocols with differences in digestive enzyme activities have been applied to rice and other starchy foods (Tables 2 and 3), which difficult the comparison of results and causes discrepancy of results among laboratories. The results of this study, obtained using the INFOGEST harmonized protocol, should represent a more realistic starch hydrolysis profile and the corresponding fate of food digesta, besides contributing to the increase of comparability of experimental results between laboratories. Generally, the results obtained here are in agreement with reports of hydrolysis profiles for other starchy foods when applying the same methodology (Bustos et al. 2017).

\section{Rapidly digestible starch, slowly digestible starch, resistant starch and glycemic index}

Through the analysis of starch hydrolysis rate and extension, rapidly digestible starch (RDS), slowly digestible starch (SDS), resistant starch (RS) and glycemic index (GI) were determined and results are presented in Table 1.

These values differ from those obtained using in vitro digestion methodologies for starch hydrolysis that do no simulate each digestive phase separately (where samples were solubilized and catalyzed with pepsin, and digestion was performed using pancreatin and amyloglucosidase) (Deepa et al. 2010; Kuang et al. 2016; Srikaeo and 
Table 3 Comparison of in vitro digestion protocols applied for starch morphological studies

\begin{tabular}{|c|c|c|c|c|c|c|c|}
\hline $\begin{array}{l}\text { Oral } \\
\text { phase }\end{array}$ & $\begin{array}{l}\text { Gastric } \\
\text { phase }\end{array}$ & Intestinal phase & Food & Initial dimension & Morphological changes & $\begin{array}{l}\text { Dimensions after } \\
\text { digestion }\end{array}$ & Reference \\
\hline \multicolumn{3}{|c|}{ INFOGEST harmonized digestion protocol } & $\begin{array}{l}\text { Three } \\
\text { "Carolino" } \\
\text { rice } \\
\text { varieties }\end{array}$ & $\begin{array}{l}\text { (After cooking) } \\
\text { Area }\left(\mu \mathrm{m}^{2}\right) \text { : } \\
\text { 1331.85-1405.21; } \\
\text { Perimeter }(\mu \mathrm{m}) \text { : } \\
\text { 141.50-145.02; } \\
\text { Diameter }(\mu \mathrm{m}) \text { : } \\
\text { 33.49-54.95 }\end{array}$ & $\begin{array}{l}\text { After } 60 \text { min (gastric } \\
\text { phase) into digestion } \\
\text { rice starch granules } \\
\text { begin to become } \\
\text { undefined; After } \\
150 \text { min (intestinal } \\
\text { phase) rice starch } \\
\text { granules were } \\
\text { disrupted }\end{array}$ & $\begin{array}{l}\text { Area }\left(\mu \mathrm{m}^{2}\right) \text { : } \\
\text { 461.21-540.70; } \\
\text { Perimeter }(\mu \mathrm{m}) \text { : } \\
\text { 81.70-88.20; } \\
\text { Diameter }(\mu \mathrm{m}) \text { : } \\
\text { 20.30-32.57 }\end{array}$ & This work \\
\hline- & $\begin{array}{l}\text { SGF } \\
\text { containing } \\
\text { pepsin } \\
(30 \mathrm{~min})\end{array}$ & $\begin{array}{l}\text { SIF containing } \\
\text { pancreatin } \\
(210 \mathrm{~min})\end{array}$ & $\begin{array}{l}\text { Polished rice } \\
\text { grain }\end{array}$ & $\begin{array}{l}\text { (Homogenized } \\
\text { cooked rice) } \\
\text { Diameter }(\mu \mathrm{m}) \text { : ca. } \\
5-50\end{array}$ & $\begin{array}{l}\text { After } 30 \text { min (gastric } \\
\text { phase) there was not } \\
\text { changes to granules } \\
\text { dimensions; } \\
\text { Dimensions after } \\
5 \text { min and } 120 \\
\text { (intestinal phase) were } \\
\text { in the same range }\end{array}$ & $\begin{array}{l}\text { (Homogenized } \\
\text { cooked rice) } \\
\text { Diameter }(\mu \mathrm{m}) \text { : } \\
\text { ca. } 1-5\end{array}$ & $\begin{array}{l}\text { Tamura } \\
\text { et al. } \\
\text { (2016) }\end{array}$ \\
\hline- & - & $\begin{array}{l}\alpha \text {-amylase }(120 \\
\mathrm{U} / \mathrm{mL}) \text { and } \\
\text { amyloglucosidase } \\
(80 \mathrm{U} / \mathrm{mL}) \\
(120 \mathrm{~min} \text { at } \\
\left.37^{\circ} \mathrm{C}\right)\end{array}$ & $\begin{array}{l}\text { Rice starch; } \\
\text { Rice starch- } \\
\text { pullulan } \\
\text { complex }\end{array}$ & - & $\begin{array}{l}\text { Small particles were } \\
\text { significantly positively } \\
\text { correlated with RS } \\
\text { (Pearson correlation); } \\
\text { Medium and large } \\
\text { particles were } \\
\text { significantly } \\
\text { negatively correlated } \\
\text { with RS }\end{array}$ & $\begin{array}{l}\text { (Small particles) } \\
\text { Diameter } \\
(\mu \mathrm{m}):<62.2 \\
\text { (Medium } \\
\text { particles) } \\
\text { Diameter }(\mu \mathrm{m}) \text { : } \\
\text { 62.2-209.3 } \\
\text { (Large particles) } \\
\text { Diameter }(\mu \mathrm{m}): \\
>209.3\end{array}$ & $\begin{array}{l}\text { Chen } \\
\text { et al. } \\
(2017)\end{array}$ \\
\hline- & - & $\begin{array}{l}\text { Pancreatic } \alpha- \\
\text { amylase }(290 \mathrm{U} / \\
\mathrm{mL}) \text { and } \\
\text { amyloglucosidase } \\
(15 \mathrm{U} / \mathrm{mL}) \\
(120 \mathrm{~min} \text { at } \\
\left.37^{\circ} \mathrm{C}\right)\end{array}$ & $\begin{array}{l}\text { Waxy maze } \\
\text { starch }\end{array}$ & $\begin{array}{l}\text { (Granules size) } \\
\text { Diameter }(\mu \mathrm{m}) \text { : } \\
\text { 5-25; Molecular } \\
\text { weight } \\
\left(10^{7} \mathrm{~g} \mathrm{~mol}^{-1}\right) \text { : } \\
21.9\end{array}$ & $\begin{array}{l}\text { Increasing enlargement } \\
\text { of holes in granules } \\
\text { and increasing } \\
\text { hydrolysis of internal } \\
\text { regions as a result of } \\
\text { longer time hydrolysis }\end{array}$ & $\begin{array}{l}\text { (Granules size) } \\
\text { Molecular weight } \\
\text { after } 20 \mathrm{~min} \\
\left(10^{7} \mathrm{~g} \mathrm{~mol}^{-1}\right) \text { : } \\
16.5 ; \text { Molecular } \\
\text { weight after } \\
120 \mathrm{~min} \\
\left(10^{7} \mathrm{~g} \mathrm{~mol}^{-1}\right) \text { : } \\
7.9\end{array}$ & $\begin{array}{l}\text { Miao } \\
\text { et al. } \\
(2011)\end{array}$ \\
\hline
\end{tabular}

Sangkhiaw 2014). Although RS content depends on the rice variety and can inclusively be modulated by postharvest processes (Azizi et al. 2019), the different methodologies used for quantification had very different output values. For instance, the studies presented in Table 2 indicate that RDS, the portion of starch hydrolysed until $30 \mathrm{~min}$ of digestion, constitutes more than $30 \%$ of the total starch. In our study, $\mathrm{Cw}, \mathrm{Cb}$ and $\mathrm{CAb}$ samples presented less than $5 \%$ of RDS, which can be explained by the inhibition of $\alpha$-amylase action in acid conditions when passing from the oral to gastric phase in INFOGEST in vitro digestion protocol, as opposed to the continuous action of pancreatin and amyloglucosidase during their incubation period with samples in optimal enzymatic conditions. In terms of $\mathrm{RS}, \mathrm{Cw}, \mathrm{Cb}$ and $\mathrm{CAb}$ samples present between 55 and $60 \%$, respectively, which also differs from the results presented by other authors (see Table 2). A higher percentage of RS is desired, because of its physiologic effects in the intestine (similar to fibres) (Topping, Fukushima, and Bird 2003), being also described as having health benefits in non-transmissible diet-related diseases (Ludwig 2002). Higher amounts of RDS and SDS are representative of foods with high GI, caused by the rapid release of glucose in digestion.

In terms of GI, all samples can be characterized as medium GI foods, since they present a GI between 55 and 70 (Brand-Miller et al. 2002), which is in agreement with the values reported in carbohydrate GI tables (Atkinson, Foster-Powell, and Brand-Miller 2008). Despite the differences between them in hydrolysis percentages and starch fractions, the GI of the samples did not present statistically significant differences $(p>0.05)$. 

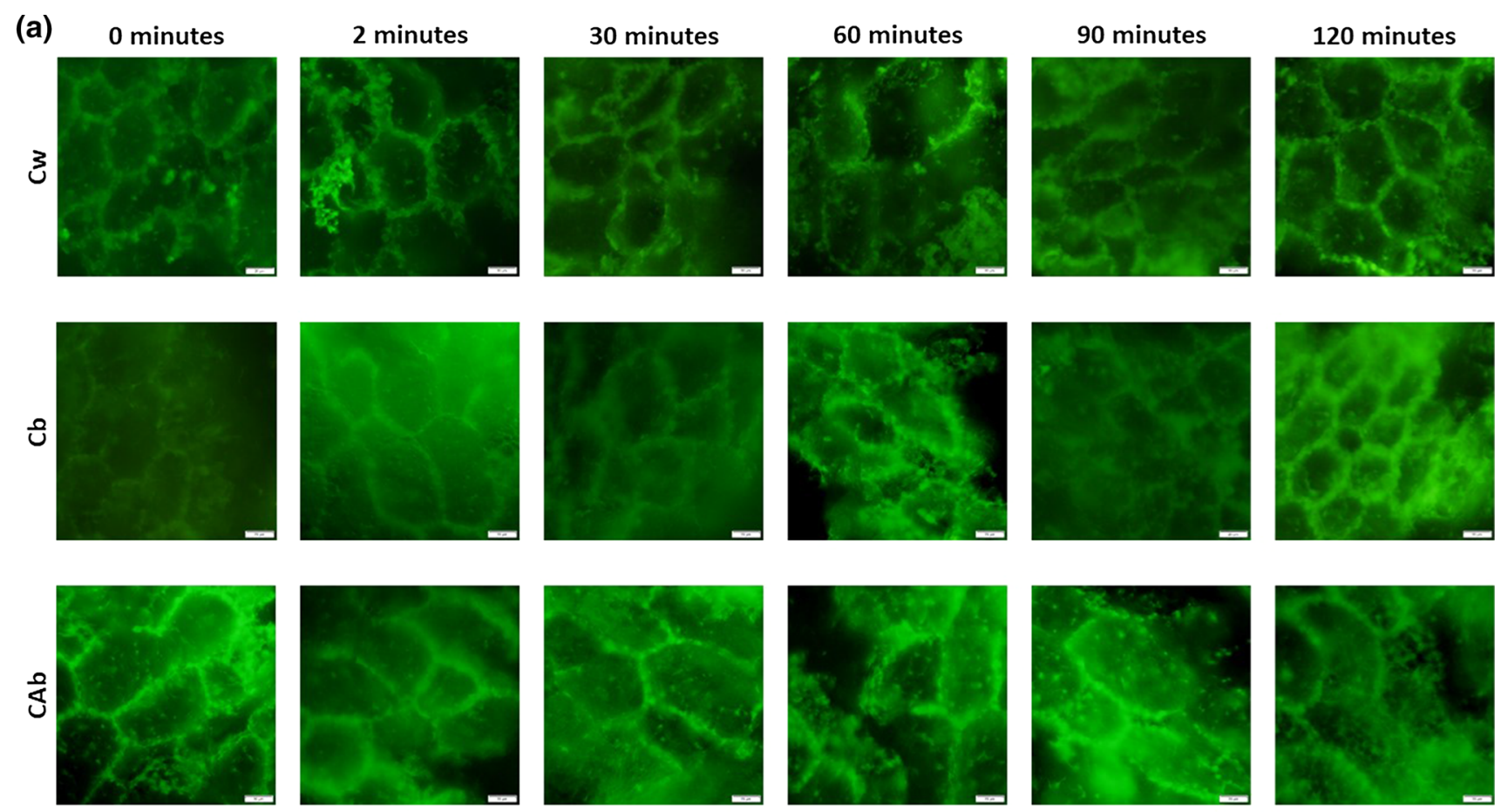

(b)

150 minutes
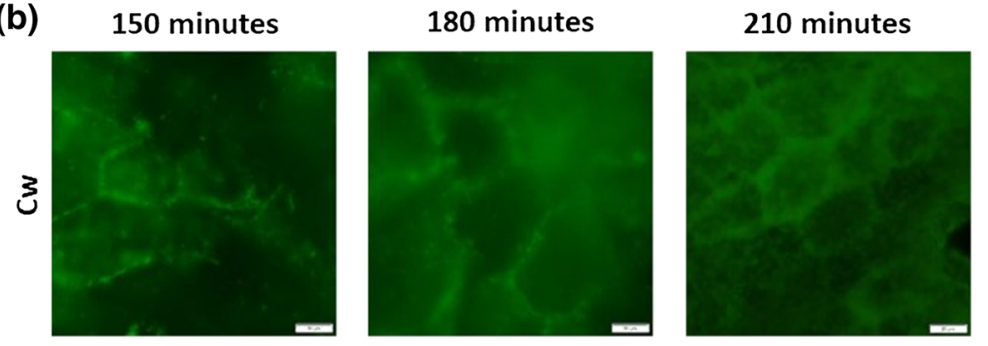

\section{0 minutes}
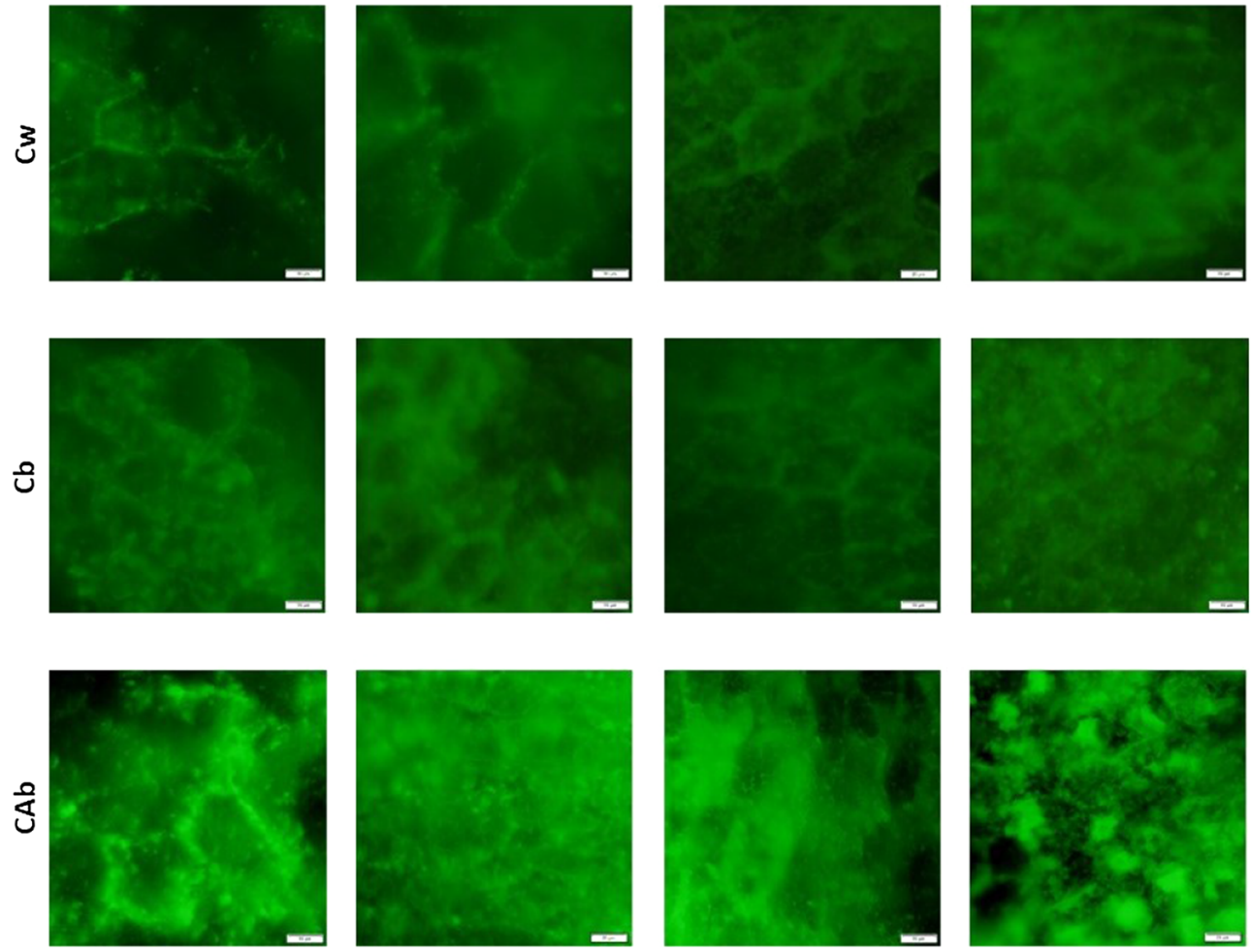

Fig. 2 Images from fluorescence microscopy $(40 \times$ magnification $)$ of the rice starch granules a prior $(0 \mathrm{~min})$ and during the oral (2 min) and gastric phases of in vitro digestion; $\mathbf{b}$ during intestinal phase of in vitro digestion. Scale bars correspond to $20 \mu \mathrm{m}$

These results support that the in vitro digestion protocol applied will influence GI and other important nutritional parameters used for food characterization, producing different outcomes that cannot be compared. For this reason, it is important to apply harmonized in vitro digestion protocols. 


\section{Morphological study of rice starch granules}

RSG are described as the smaller starch granules found in staple foods in their native state, with a diameter from 2 to $7 \mu \mathrm{m}$, reaching up to $100 \mu \mathrm{m}$ in diameter after cooking (Patindol, Siebenmorgen, and Wang 2015). FITC was the selected staining agent for the assays because of its reactivity towards sulfhydryl groups of proteins and slower fluorescence decay observed on the tested samples (van de Velde et al. 2002).

Figure $2 \mathrm{a}$ represents the RSG images of the initial samples until the end of the gastric phase (0-120 min).

After cooking, the RSG of the three samples presented a circular/hexagonal shape, which is in accordance with previous morphological studies (Tamura et al. 2016). RSG did not present visible arrangement or structural differences after 2 min of digestion (mouth simulation). RSG structure starts to become more undefined after $60 \mathrm{~min}$. Until the end of the gastric phase (i.e., $120 \mathrm{~min}$ ), RSG present a decrease in dimensions, particularly visible on
$\mathrm{Cb}$, which was also the sample that had a higher total starch hydrolysis described previously.

As observed for the hydrolysis profile of the three samples, the peak of degradation was observed at $150 \mathrm{~min}$, which corresponds to the first image of the intestinal phase presented in Fig. 2b. At this point, the observation of complete RSG was not possible, and only disrupted portions of the exterior membrane and the microstructures of starch were visible. Until the end of the digestion, RSG with smaller dimensions were visible, presumably due to a rearrangement of starch granules after the peak of hydrolysis as suggested before. Similar outcomes, presented in Table 3, were observed using other in vitro digestion methodologies, although, it can be concluded that the description of RDS and SDS morphology is lacking. On the other hand, RSG observed at the end of the digestion process can be a representation of RS morphology, since it corresponds to starch that was not hydrolyzed, thus having resisted to the digestion process.
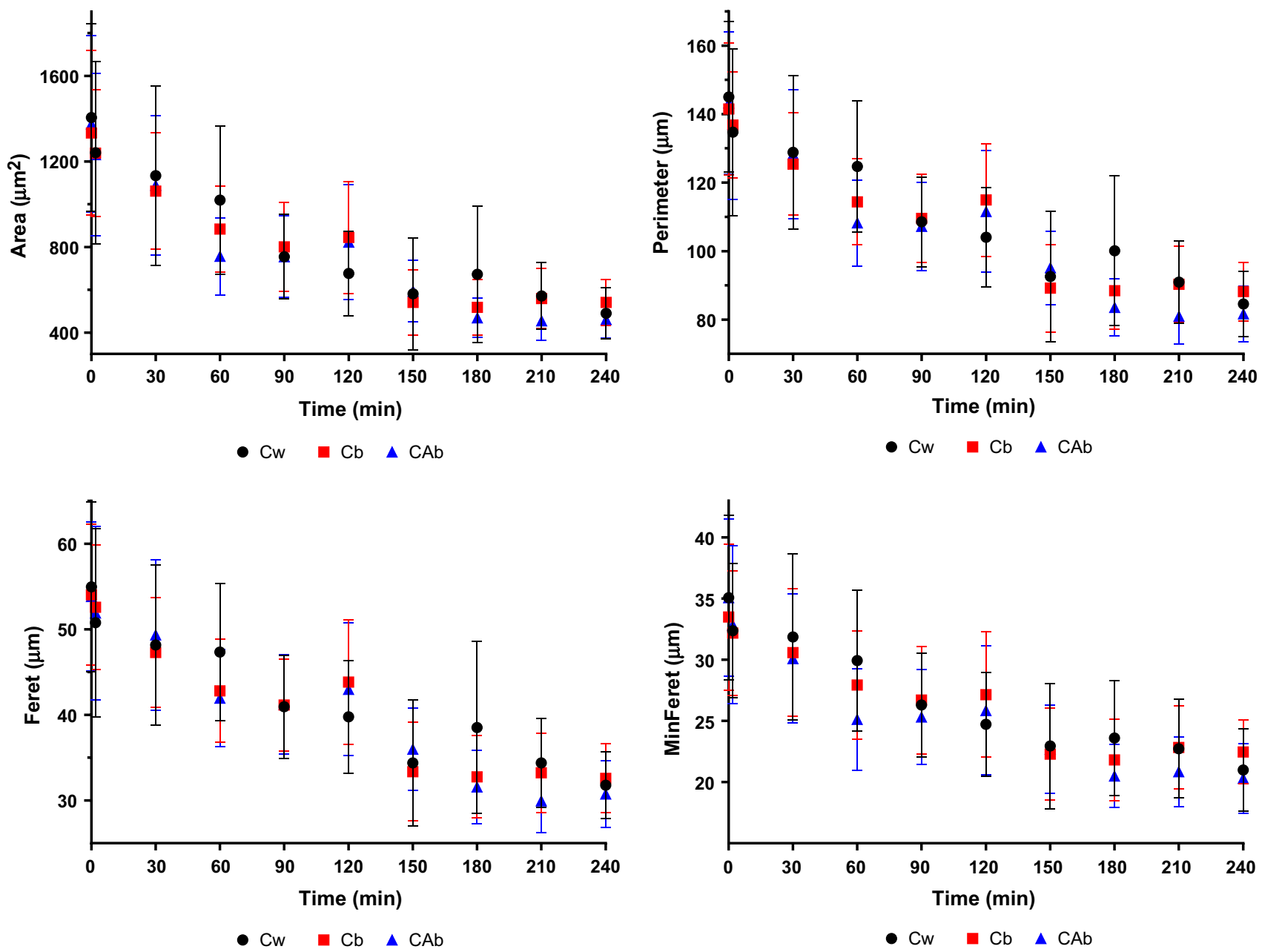

Fig. 3 RSG measurements of $\mathrm{Cw}, \mathrm{Cb}$ and $\mathrm{CAb}$ during in vitro digestion. Measurements were made in Imagej software, allowing the determination of area, perimeter, Feret diameter and minimum Feret diameter. Dots represent the mean and bars represent the standard deviation 
The variation of the RSG dimensions during the digestion process are presented in Fig. 3. All samples presented a similar behavior, with a continuous decrease in all dimensional parameters. RSG of the sample $\mathrm{Cw}$ presented higher initial dimensions and the most significant decrease in dimensions. With the milling process, and consequent bran removal, $\mathrm{Cw}$ endosperm surface area becomes more available to enzymatic degradation (Boers et al. 2015). When comparing the two brown rice samples, despite $\mathrm{Cb}$ having higher GI, the RSG of the sample CAb exhibited higher dimensional decrease, presenting the smallest dimensions at the end of the digestion process. In the case of $\mathrm{Cw}$ and $\mathrm{CAb}$, although RSG had similar dimensional decrease, samples presented different hydrolysis percentages and rates, which can be associated to their kernels.

With these results, it can be concluded that RSG morphological changes can be important for the study and determination of starch fractions, starch hydrolysis and hydrolysis rates, which are determinant factors for GI prediction.

\section{Conclusions}

In conclusion, the three Carolino rice varieties tested can be classified as long grain rice, with medium GI. The percentage of total starch was higher in the sample that was milled (i.e., $\mathrm{Cw}$ ), supporting that post-harvesting processes have high impact on sample characteristics. The importance of amylose during digestion was also confirmed, since the sample with lower amylose content (i.e., $\mathrm{Cb}$ ) presented the highest percentage of total starch hydrolyzed at the end of the digestion and lower percentage of RS. Also, this work highlights the importance of the application of a harmonized in vitro digestion protocol, once it allows interlaboratorial comparisons. Its application to understand rice starch hydrolysis along with morphological changes of RSG during the process can be fundamental to provide a better insight of the effects caused by post-harvest processing and cooking procedures of rice. Applying uniform methodologies will facilitate the information flow and allow a better correlation between food nutritional properties and starch characteristics, which can be important in the preparation of rice-based food products (or, more generally, carbohydrates-based foods), presumably resulting in the formulation of lower GI foods. In that sense, this work provides a possible interlaboratory comparison basis for future works.

Acknowledgements Daniel A. Madalena acknowledge the Foundation for Science and Technology (FCT) for his fellowship (SFRH/BD/ 129127/2017). This work was supported by Portuguese Foundation for Science and Technology (FCT) under the scope of the strategic funding of UID/BIO/04469/2019 unit and BioTecNorte operation
(NORTE-01-0145-FEDER-000004) funded by the European Regional Development Fund under the scope of Norte2020 - Programa Operacional Regional do Norte. The authors would also like to thank the investment project $\mathrm{n}^{\circ} 017931$ - Development of rice products with low glycemic index- co-funded by Fundo Europeu de Desenvolvimento Regional (FEDER) through Programa Operacional Competitividade e Internacionalização (COMPETE 2020) (POCI-010247-FEDER-017931).

\section{References}

Atkinson FS, Foster-Powell K, Brand-Miller JC (2008) International tables of glycemic index and glycemic load values: 2008 . Diabetes Care 31(12):2281-2283. https://doi.org/10.2337/dc081239

Azizi R, Capuano E, Nasirpour A, Pellegrini N, Golmakani MT, Hosseini SMH, Farahnaky A (2019) Varietal differences in the effect of rice ageing on starch digestion. Food Hydrocoll 95(March):358-366. https://doi.org/10.1016/j.foodhyd.2019.04. 057

Björck I, Granfeldt Y, Liljeberg H, Tovar J, Georg Asp N (1994) Food properties affecting the digestion and absorption of carbohydrates. Am J Clin Nutr 59:699S-705S. https://doi.org/ 10.1093/ajcn/59.3.699S

Boers HM, Hoorn JST, Mela DJ (2015) A systematic review of the influence of rice characteristics and processing methods on postprandial glycaemic and insulinaemic responses. Br J Nutr. https://doi.org/10.1017/S0007114515001841

Brand-Miller JC, Holt SH, Pawlak DB, McMillan J (2002) Glycemic index and obesity. Am J Clin Nutr 76(1):281S-285S. https://doi. org/10.1093/ajcn/76/1.281s

Bustos MC, Vignola MB, Pérez GT, León AE (2017) In Vitro digestion kinetics and bioaccessibility of starch in cereal food products. J Cereal Sci 77:243-250. https://doi.org/10.1016/j.jcs. 2017.08.018

Chang UJ, Hong YH, Jung EY, Suh HJ (2014) Rice and the glycemic index. Wheat Rice Dis Prev Health. https://doi.org/10.1016/ B978-0-12-401716-0.00027-1

Chen L, Tian Y, Zhang Z, Tong Q, Sun B, Rashed Marwan MA, Jin Z (2017) Effect of pullulan on the digestible, crystalline and morphological characteristics of rice starch. Food Hydrocoll 63:383-390. https://doi.org/10.1016/j.foodhyd.2016.09.021

Deepa G, Singh V, Akhilender Naidu K (2010) A comparative study on starch digestibility, glycemic index and resistant starch of pigmented ('Njavara' and'Jyothi') and a non-pigmented ('IR 64') rice varieties. J Food Sci Technol 47(6):644-649. https:// doi.org/10.1007/s13197-010-0106-1

Egger L, Ménard O, Delgado-Andrade C, Alvito P, Assunção R, Balance S, Barberá R et al (2016) The harmonized INFOGEST in Vitro digestion method: from knowledge to action. Food Res Int 88(October):217-225. https://doi.org/10.1016/j.foodres.2015. 12.006

Englyst KN, Englyst HN, Hudson GJ, Cole TJ, Cummings JH (1999) Rapidly available glucose in foods: an in vitro measurement that reflects the glycemic response. Am J Clin Nutr 69(3):448-454. https://doi.org/10.1093/ajen/69.3.448

Goñi I, Garcia-Alonso A, Saura-Calixto F (1997) A starch hydrolysis procedure to estimate glycemic index. Nutr Res 17(3):427-437. https://doi.org/10.1016/S0271-5317(97)00010-9

Jenkins DJA, Kendall CWC, Augustin LSA, Franceschi S, Hamidi M, Marchie A, Jenkins AL, Axelsen M (2002) Glycemic index: overview of implications in health and disease. Am J Clin Nutr 76(1):266S-273S. https://doi.org/10.1093/ajcn/76/1.266S 
Joint FAO/WHO Codex Alimentarius International Food Standards (2019) Codex alimentarius: Standard for rice CXS 198-1995. http://www.fao.org/fao-who-codexalimentarius/codex-texts/liststandards/. Accessed 25 Nov 2018

Juliano BO (1993) FAO Food and Nutrition Series No. 26 RICE in human nutrition prepared in collaboration with FAO By. http:// books.irri.org/9251031495_content.pdf. Accessed 13 Oct 2018

Kuang Q, Jinchuan X, Wang K, Zhou S, Liu X (2016) Structure and digestion of hybrid indica rice starch and its biosynthesis. Int $\mathrm{J}$ Biol Macromol 93:402-407. https://doi.org/10.1016/j.ijbiomac. 2016.08.023

Ludwig DS (2002) The glycemic index. JAMA 287(18):2414. https:// doi.org/10.1001/jama.287.18.2414

Miao M, Zhang T, Wanmeng M, Jiang B (2011) Structural characterizations of waxy maize starch residue following in vitro pancreatin and amyloglucosidase synergistic hydrolysis. Food Hydrocoll 25(2):214-220. https://doi.org/10.1016/j.food hyd.2009.12.004

Minekus M, Alminger M, Alvito P, Ballance S, Bohn T, Bourlieu C, Carrière $\mathrm{F}$ et al (2014) A standardised static in vitro digestion method suitable for food-an international consensus. Food Funct 5(6):1113-1124. https://doi.org/10.1039/C3FO60702J

Muthayya S, Sugimoto JD, Montgomery S, Maberly GF (2014) An overview of global rice production, supply, trade, and consumption. Ann NY Acad Sci 1324(1):7-14. https://doi.org/10.1111/ nyas. 12540

Nobre C, Sousa SC, Silva SP, Pinheiro AC, Coelho E, Vicente AA, Gomes AMP, Coimbra MA, Teixeira JA, Rodrigues LR (2018) In Vitro digestibility and fermentability of fructo-oligosaccharides produced by Aspergillus ibericus. J Funct Foods 46(July):278-287. https://doi.org/10.1016/J.JFF.2018.05.004

Patindol JA, Siebenmorgen TJ, Wang Y-J (2015) Impact of environmental factors on rice starch structure: a review. Starch Stärke 67(1-2):42-54. https://doi.org/10.1002/star.201400174

Pérez S, Bertoft E (2010) The molecular structures of starch components and their contribution to the architecture of starch granules: a comprehensive review. Starch Stärke 62(8):389-420. https://doi.org/10.1002/star.201000013

Ramos PE, Abrunhosa L, Pinheiro A, Cerqueira MA, Motta C, Castanheira I, Chandra-Hioe MV, Arcot J, Teixeira JA, Vicente AA (2016) Probiotic-loaded microcapsule system for human in situ folate production: encapsulation and system validation. Food Res Int 90(December):25-32. https://doi.org/10.1016/J. FOODRES.2016.10.036

Ren X, Chen J, Molla MM, Wang C, Diao X, Shen Q (2016) In Vitro starch digestibility and in vivo glycemic response of foxtail millet and its products. Food Function 7(1):372-379. https://doi. org/10.1039/c5fo01074h

Rodrigues DB, Chitchumroonchokchai C, Mariutti Lilian R B, Mercadante AZ, Failla ML (2017) Comparison of two static in vitro digestion methods for screening the bioaccessibility of carotenoids in fruits, vegetables, and animal products. J Agric Food Chem 65(51):11220-11228. https://doi.org/10.1021/acs. jafc.7b04854

Roy P, Ijiri T, Okadome H, Nei D, Orikasa T, Nakamura N, Shiina T (2008) Effect of processing conditions on overall energy consumption and quality of rice (Oryza Sativa L.). J Food Eng 89(3):343-348. https://doi.org/10.1016/j.jfoodeng.2008.05.015

Santos T, Lemos D, Guiné RPF, Correia PR (2014) Biometric characteristics of rice cultivars. In VII Congreso Ibérico de Agroingenieria y Ciencias Hortícolas: Innovar y Producir para el Futuro. Madrid. F. G. UPM, ed.:174-179. ISBN:84-695-9055-3

Srikaeo K, Sangkhiaw J (2014) Effects of amylose and resistant starch on glycaemic index of rice noodles. LWT Food Sci Technol 59(2):1129-1135. https://doi.org/10.1016/j.lwt.2014.06.012

Tamura M, Singh J, Kaur L, Ogawa Y (2016) Impact of structural characteristics on starch digestibility of cooked rice. Food Chem 191:91-97. https://doi.org/10.1016/j.foodchem.2015.04.019

Tamura M, Okazaki Y, Kumagai C, Ogawa Y (2017) The importance of an oral digestion step in evaluating simulated in vitro digestibility of starch from cooked rice grain. Food Res Int 94(April):6-12. https://doi.org/10.1016/j.foodres.2017.01.019

Tester RF, Qi X, Karkalas J (2006) Hydrolysis of native starches with amylases. Anim Feed Sci Technol 130(1-2):39-54. https://doi. org/10.1016/J.ANIFEEDSCI.2006.01.016

Topping DL, Fukushima M, Bird AR (2003) Resistant starch as a prebiotic and synbiotic: state of the art. Proc Nutr Soc 62(01):171-176. https://doi.org/10.1079/PNS2002224

van de Velde F, van Riel J, Tromp RH (2002) Visualisation of starch granule morphologies using confocal scanning laser microscopy (CSLM). J Sci Food Agric 82(13):1528-1536. https://doi.org/10. 1002/jsfa. 1165

Whitcomb DC, Lowe ME (2007) Human pancreatic digestive enzymes. Dig Dis Sci 52(1):1-17. https://doi.org/10.1007/ s10620-006-9589-Z

Woolnough JW, Bird AR, Monro JA, Brennan CS (2010) The effect of a brief salivary $\alpha$-amylase exposure during chewing on subsequent in vitro starch digestion curve profiles. Int J Mol Sci 11(8):2780-2790. https://doi.org/10.3390/ijms11082780

Publisher's Note Springer Nature remains neutral with regard to jurisdictional claims in published maps and institutional affiliations. 